\title{
Multi-level consistent changes of the ECM pathway identified in a typical keratoconus twin's family by multi-omics analysis
}

\author{
Xiao-dan Hao ${ }^{1,2+}$, Xiu-nian Chen ${ }^{1,2+}$, Yang-yang Zhang ${ }^{2}$, Peng Chen ${ }^{3}$, Chao Wei ${ }^{2}$, Wei-yun Shi ${ }^{2,4}$ and Hua Gao ${ }^{2,4^{*}}$ (D)
}

\begin{abstract}
Background: Keratoconus $(\mathrm{KC})$ is a common, degenerative disorder of the cornea, and genetic factors play a key role in its development. However, the genetic etiology of $\mathrm{KC}$ is still unclear. This study used the family of twins as material, using, for the first time, multi-omics analysis, to systematically display the changes in $\mathrm{KC}$ candidate factors in patients at the DNA, RNA, and protein levels. These can evaluate candidate pathogenic factors in depth and lock onto pathogenic targets.
\end{abstract}

Results: The twins in this study presented classic phenotypes, clear diagnoses, complete case data, and clinical samples, which are excellent materials for genetically studying KC. Whole-exome sequencing was conducted on both the twins and their parents. Transcriptome sequencing was conducted on proband's and health individual's primary human corneal fibroblast cells. Quantitative Real-time PCR and western blot were used to validate the differential gene expressions between the proband and controls. By integrating genomics, transcriptome, and protein level data, multiple consecutive events of $\mathrm{KC}$ were systematically analyzed to help better understand the molecular mechanism and genetic basis of KC. The results showed that the accumulation of rare, micro-effect risk variants was the pathogenic factor in this Chinese KC family. Consistent changes in extracellular matrices (ECMs) at the DNA and RNA levels suggested that ECM related changes play a key role in KC pathogenesis. The major gene variants (WNT16, CD248, COL6A2, COL4A3 and ADAMTS3) may affect the expression of related collagens or ECM proteins, thus reducing the amount of ECM in corneas and resulting in KC.

Conclusions: This study, the first to explore the genetic etiology of KC via multi-omics analysis under the polygenetic model, has provided new insights into the genetic mechanisms underlying KC and an effective strategy for studying KC pathogenesis in the future.

Keywords: Keratoconus, Multi-Omics analysis, Polygene, ECM

\footnotetext{
*Correspondence: gaohua100@126.com

${ }^{+}$Xiao-dan Hao and Xiu-nian Chen are co-first authors

${ }^{2}$ State Key Laboratory Cultivation Base, Shandong Provincial Key Laboratory

of Ophthalmology, Shandong Eye Institute, Shandong First Medical

University \& Shandong Academy of Medical Sciences, Qingdao 266071,

China

${ }^{4}$ Shandong Eye Hospital, Shandong Eye Institute, Shandong First Medical University \& Shandong Academy of Medical Sciences, Jinan 250021, China

Full list of author information is available at the end of the article
}

(c) The Author(s). 2020 Open Access This article is licensed under a Creative Commons Attribution 4.0 International License, which permits use, sharing, adaptation, distribution and reproduction in any medium or format, as long as you give appropriate credit to the original author(s) and the source, provide a link to the Creative Commons licence, and indicate if changes were made. The images or other third party material in this article are included in the article's Creative Commons licence, unless indicated otherwise in a credit line to the material. If material is not included in the article's Creative Commons licence and your intended use is not permitted by statutory regulation or exceeds the permitted use, you will need to obtain permission directly from the copyright holder. To view a copy of this licence, visit http://creativecommons.org/licenses/by/4.0/ The Creative Commons Public Domain Dedication waiver (http://creativecommons.org/publicdomain/zero/1.0/) applies to the data made available in this article, unless otherwise stated in a credit line to the data. 


\section{Background}

Keratoconus (KC) is a complex, genetically heterogeneous, multifactor degenerative disorder of the cornea with a worldwide prevalence of approximately 1:2000 [1-4]. It is characterized by corneal ectasia, thinning, and coneshaped protrusion, resulting in reduced vision, irregular astigmatism, and corneal scarring [1-4]. Because of the unclear pathogenesis and limited availability of medical treatments, $\mathrm{KC}$ becomes a significant clinical problem worldwide and a leading indication for corneal transplantation [5]. Previous studies have shown that genetic factors are involved in the $\mathrm{KC}$ development $[2,6,7]$, and, thus, $\mathrm{KC}$ has a clear genetic tendency. About $6-10 \%$ of $\mathrm{KC}$ patients have a family history of $\mathrm{KC}$, and its incidence in patients' immediate relatives is 60 times higher than the incidence in people who are not immediate relatives of $\mathrm{KC}$ patients [8]. The genetic mode for $\mathrm{KC}$ development is autosomal dominant inheritance with incomplete exodominant or recessive inheritance $[7,8]$. $\mathrm{KC}$ studies among twins show that monozygotic twins display higher genetic consistency than heterozygotic twins, which proves that genetic factors have an important contribution towards the pathogenesis of $\mathrm{KC}[8,9]$.

Therefore, scholars have conducted much research on the genetic causes of KC. So far, more than 30 candidate genes and regions have been screened and identified by genome-wide linkage analysis, whole-exome sequencing (WES), or candidate gene sequencing [7, 8, 10-13]. However, very few of these genes have been assessed for rare variation in keratoconus more broadly [14-18]. The mutation rate of these genes in the $\mathrm{KC}$ population were very low, and even cannot be detected in many populations [14-21]. The existing candidate genes can only explain a small proportion of the incidence of $\mathrm{KC}$. Thus, the cause of $\mathrm{KC}$ in a large number of patients is still unknown [16, 21, 22].

The screening of susceptible loci is another important method for exploring the genetic causes of complex diseases. Although some KC-related loci have been found, many of them cannot be validated in other populations or in wider ranges of disease populations [17, 23, 24]. Most of the common single-nucleotide polymorphisms (SNPs) that have been located are marker loci rather than pathogenic mutations, which can only explain a small part of the heritability of KC. Therefore, these associated SNPs have a limited effect on the prediction of disease risk but have not achieved ideal results. Due to the genetic heterogeneity and population differences among $\mathrm{KC}$ patients, the genetic cause of most cases has not been effectively solved, and the pathogenesis underlying the genetic mutation is still unclear. This has become the bottleneck of $\mathrm{KC}$ genetic etiology research, so it is very important to find a breakthrough point to explore the key pathogenic genes, and the common pathogenesis, of $\mathrm{KC}$.
Twins are excellent materials for researching human traits and disease genetics. This study chose a family with $\mathrm{KC}$ monozygotic twins. The identical clinical symptom of the twins indicated the existence of genetic factors in the family. This provided precious samples for the study of the genetic mechanism of KC. Multi-omics analysis is an effective strategy for studying pathogenesis in complex diseases [25-27], but it has not been used to explore the $\mathrm{KC}$ pathogenesis. To further explore the genetic etiology of $\mathrm{KC}$ and reveal its pathogenesis, this study used a family with twins as material - for the first time through the joint analysis of multi-omics - to explore the candidate pathogenic genes of $\mathrm{KC}$, as well as the pathogenic mechanisms underlying the mutations.

\section{Results}

\section{Clinical features}

The pedigree of this family is shown in Fig. 1a. The proband individual (II-1) and her twin sister (II-2), aged 28, were born from an uneventful pregnancy. The proband patient's eyes had been ametropic since childhood, and her vision could not be corrected before half a year of hospitalization. She presented to the hospital for medical treatment and was diagnosed with bilateral $\mathrm{KC}$. The vision of the proband right eye (OD) is $0.02(0.3 \times-8.50 \mathrm{DS})$, and the vision of the left eye (OS) is $0.02(0.4 \times-8.00 \mathrm{DS})$. Both her eyes have corneal ectasia, thinning, superficial scarring, and a cone-shaped protrusion with Vogt's striae, Fleischer's ring, and Munson's sign (Fig. 1b-c). The results of anterior segment optical coherence tomography (OCT) showed that the thinnest corneal thickness of the left eye is $328 \mu \mathrm{m}$, and that of the right eye is $365 \mu \mathrm{m}$ (Fig. 1c). The proband patient's signs of videokeratography showed typical KC characteristics, including max corneal curvature $>90 \mathrm{D}$, thinnest corneal thickness $<300 \mu \mathrm{m}$, max front elevation $>120$ and max back elevation $>200$ (Fig. 2a).

Clinical examination results showed that the proband individual's twin sister was a KC patient too. Her slit lamp photographs (Fig. 1b), OCT (Fig. 1c) and videokeratography (Fig. 2a) results showed her to have similar symptoms to her proband twin, but the development process was lighter and slower. Their parents' symptoms were not great enough to diagnose $\mathrm{KC}$, but they did present some subclinical manifestations. For example, the father's (I-1) signs of videokeratography showed that his max corneal curvature was 48D; his max back elevation was 29; and his thinnest corneal thickness was $481 \mu \mathrm{m}$ (Fig. 2b, Additional file 1: Table S1). The mother's (I-2) signs of videokeratography showed that her max corneal curvature was $47 \mathrm{D}$, and her thinnest corneal thickness was $502 \mu \mathrm{m}$ (Fig. 2c, Additional file 1: Table S1). The remaining detailed clinical informations for the family are shown in Additional file 1 (Table S1). The clinical manifestations in this family were complex 

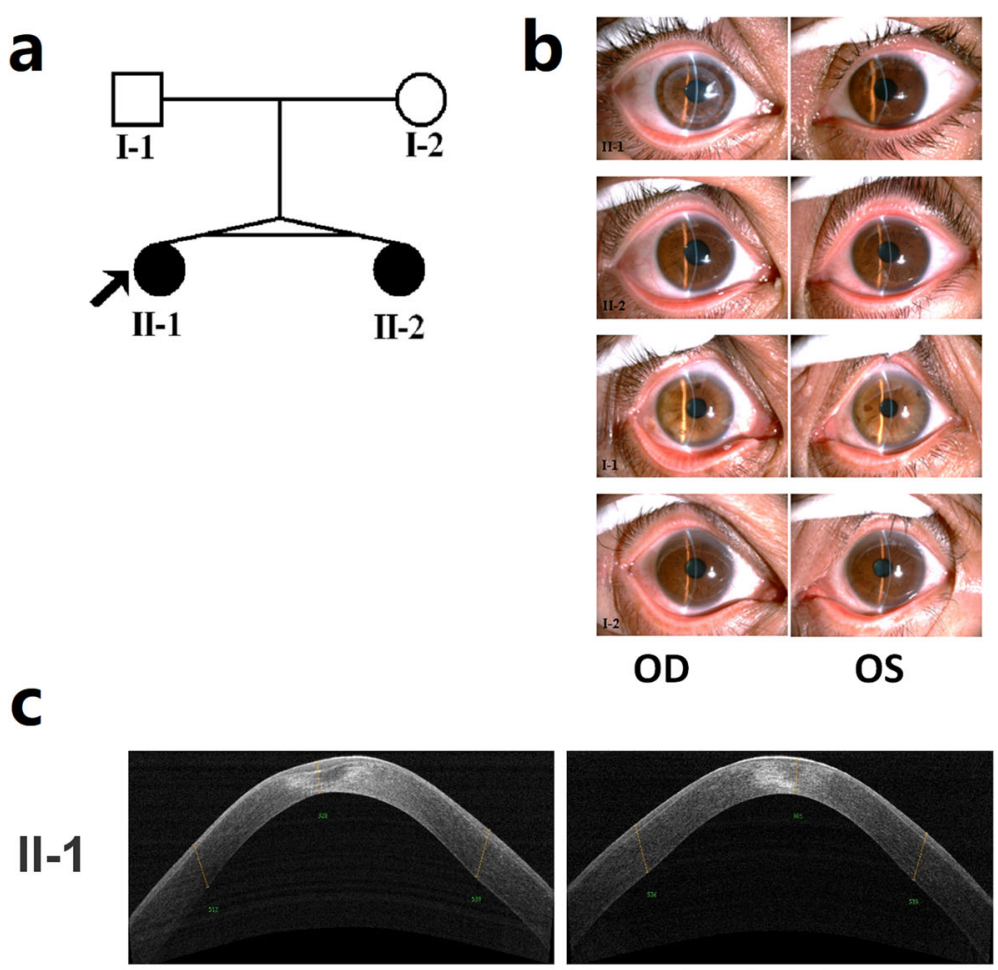

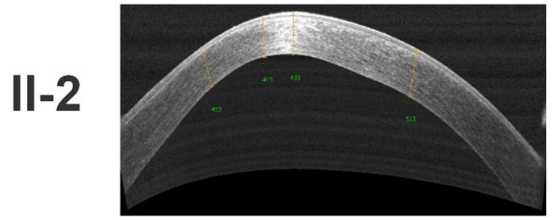

OD

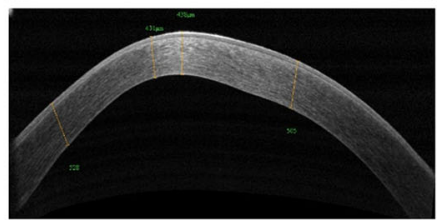

OS

Fig. 1 Pedigree and patients' cornea OCT of the family of twins with KC. a Pedigree of the twins' family. The proband is indicated by an arrow. b Slit lamp photographs of the twins' family. The OD of II-1 was the post-operative photograph, and the rest were the pre-operative photographs. c OCT of patients' corneas. The results showed high central corneal curvature and thinning of the corneal thickness in both eyes. $O D$, right eye. OS, left eye

and incomplete consistent with the characteristics of Mendelian disease, which suggested that the inheritance pattern in the family might be polygenetic.

\section{Exome sequencing detects candidate gene variants under different genetic models}

To reveal the underlying genetic defect in this family, the researchers conducted WES on four core members: the twins and their parents. The average sequencing depth and coverage of this analysis were $61.1 \times$ and $99.75 \%$, respectively. With the data analysis and variants, as well as the filtering strategy described in the methods section, 283 indels and 76 SNPs of the twin patients were retained. Details of the variation types and distributions are shown in Fig. 3a. The gene ontology (GO) analysis results of all variants were shown in Fig. 3b. The researchers filtered the candidate gene variants under different genetic models, as described in the methods section, and the results were shown in Table 1 . All the candidate gene variants obtained by WES were confirmed by Sanger sequencing (Additional file 1: Figure S1). Given the characteristics of the family's pedigree (Fig. 1a), homozygous, compound heterozygous, or de novo variations were considered the first to be considered as candidate causal variations.

First, the researchers filtered the remaining variations with the reported candidate genes and found a missense variant in COL4A3 (NM_000091.4:c.4607 T > C, p. I1536T). The variant c.4607 T > C (p. I1536T) was absent from 1000 Genomes (1000G) but was recorded in the ExAC database ( 1 heterozygous). Functional prediction under different tools all showed that this variant was "damaging" (SIFT, MutationTaster) or possibly damaging (PolyPhen2). However, this variant was not cosegregation with the phenotype of the family (Fig. 1a, Table 1). According to the ACMG (American College of Medical 


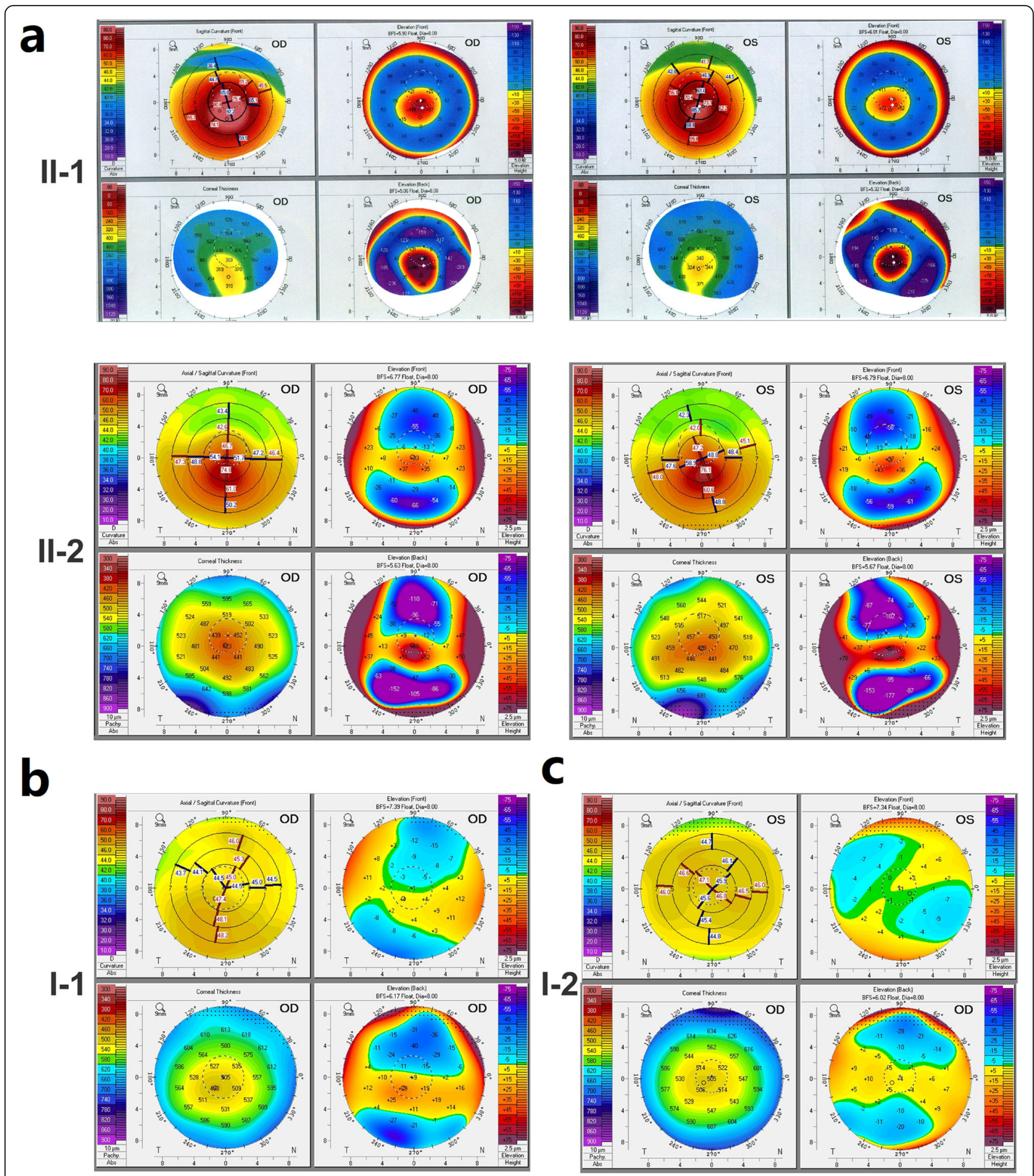

Fig. 2 Corneal topographies of the twins' family. a Corneal topographies (including curvature, corneal thickness, front elevation, and back elevation) of the twins (KC patients). $\mathbf{b}$ Risk manifestations of the twins' father. c Risk manifestations of the twins' mother. OD, right eye. OS, left eye

Genetics and Genomics) standards and guidelines [28], c.4607 T > C in COL4A3 (PM2, PP2, PP3 and BS4) was uncertain significance, indicating that it was not the cause or not the only cause of the disease.
Of all retained variants, only the PKDREJ gene with compound heterozygous variants (NM_006071.1:c.2708 T > C, p.I903T; c.1780C > G, p.L594V) was identified under the autosomal recessive model (Table 1). c.2708 


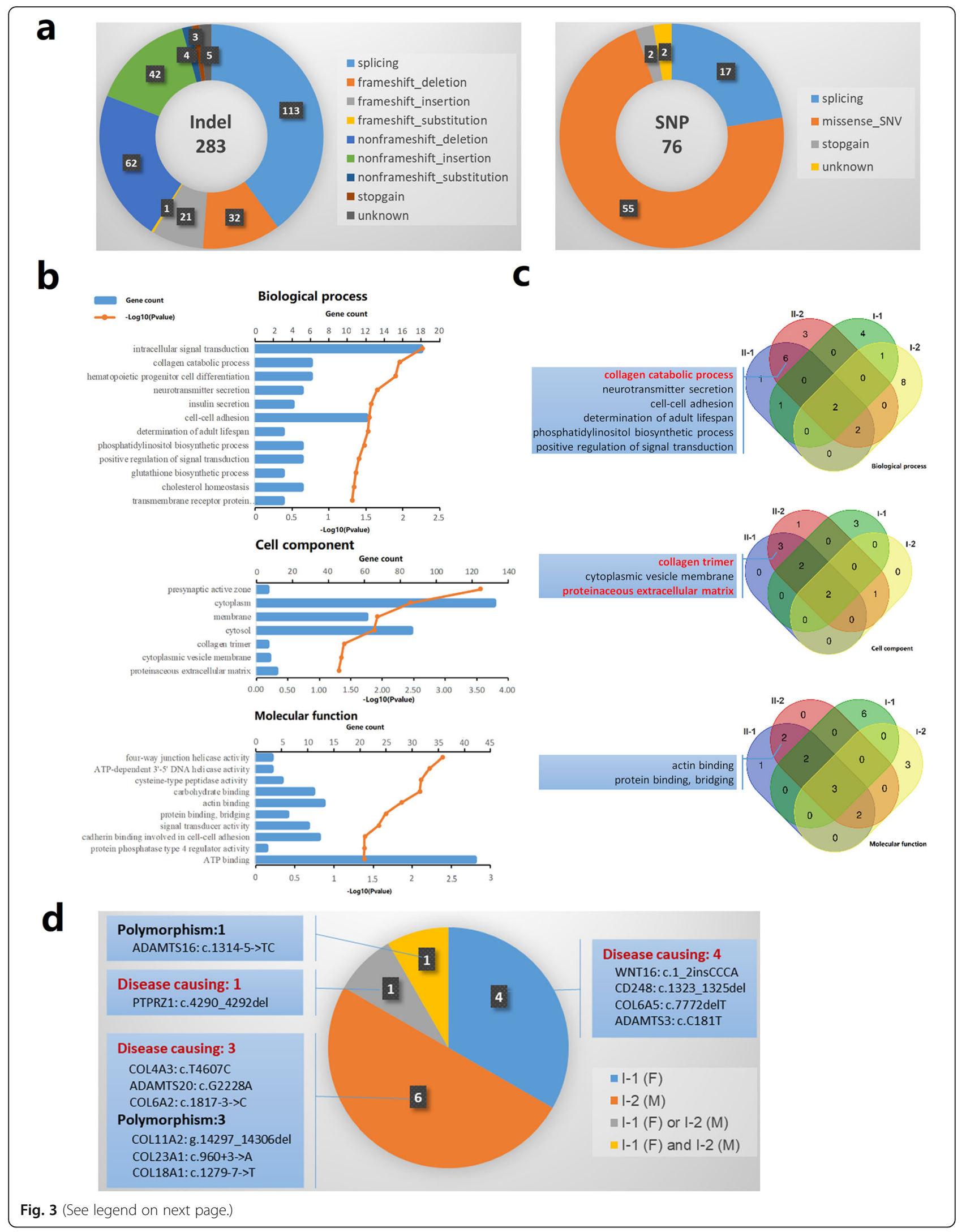


(See figure on previous page.)

Fig. 3 Mutations detected by whole exome sequencing. a The detailed mutation types and distribution of the mutations in the twin patients retained after filtering. $\mathbf{b}$ GO analysis results of all mutations retained. c The specific GOs of the twin patients compared to their parents. The GOs having similar functions with the reported pathogenesis of KC are indicated by red color. $\mathbf{d}$ Function prediction and sources of 12 candidate gene mutations under the polygenetic model

T > C (p.I903T) was absent from 1000 Genomes (1000G) but was recorded in the ExAC database. It was considered a "polymorphism" as predicted by MutationTaster and PolyPhen2. c.1780C > G (p.L594V) was recorded in the 1000G (rs533899886) but had a very low allele frequency $(<0.0002)$. Functional prediction under different tools all showed that this variant was "damaging" (SIFT, MutationTaster) or possibly damaging (PolyPhen2). According to the ACMG standards and guidelines, variants in PKDREJ (PM2, PP1) were uncertain significance.

To detect the de novo variations, the researchers compared the sequencing results from the twins to those of their parents. Three genes with de novo variants were identified, but only one variation in the FGA gene (NM_000508.4:c.709 T > C, p.F237L) was found in the functional region and caused amino acid changed (Table 1). This variant was found neither in the ExAC nor the 1000G databases. However, it was considered a "polymorphism," as predicted by MutationTaster and PolyPhen2, indicating that it might be a benign variation. According to the ACMG standards and guidelines, variant in FGA (PS2, PM2, PP1) was likely pathogenic with a contradiction (BP4).

The clinical manifestations of this $\mathrm{KC}$ family were incomplete consistent with the characteristics of Mendelian disease. The reported candidate gene variation (COL4A3: c. $4607 \mathrm{~T}>\mathrm{C}$ ) cannot fully explain the cause of the disease. All of these suggested that the twins' pathogenesis was probably due to multiple micro-effect variants provided by their parents. Therefore, the researchers also analyzed the variations under the polygenic genetic model. Because of the combination of parental risk variations, these twin patients were likely to have some significant different GO enrichments compared to their parents, which suggested the possible causes of the disease in this family. The specific GOs of the twin patients are shown in Fig. 3c, including six biological processes, three cell components, and two molecular functions. In these specific GOs, one biological process (the collagen catabolic process) and two cell components (collagen trimer and the proteinaceous extracellular matrix (ECM)) function similarly to the

Table 1 The candidate gene variants under different genetic models

\begin{tabular}{|c|c|c|c|c|c|c|}
\hline Gene & Mutation types & Nucleotide change & Amino acid change & $\begin{array}{l}\text { Mutation } \\
\text { Taster }\end{array}$ & Source & $\begin{array}{l}\text { Genetic } \\
\text { models }\end{array}$ \\
\hline PKDREJ & missense_SNV & NM_006071.1:C.2708 T > C & NP_006062.1:p.(Ile903Thr) & polymorphism & $1-1(F)$ & \multirow{2}{*}{$\begin{array}{l}\text { autosomal } \\
\text { recessive }\end{array}$} \\
\hline PKDREJ & missense_SNV & NM_006071.1:c.1780C > G & NP_006062.1:p.(Leu594Val) & disease causing & $\mathrm{I}-2(\mathrm{M})$ & \\
\hline FGA & missense_SNV & NM_000508.4:C.709 T > C & $\begin{array}{l}\text { NP_000499.1(LRG_557p1): } \\
\text { p.(Phe237Leu) }\end{array}$ & polymorphism & de novo & de novo \\
\hline WNT16 & frameshift_insertion & NM_016087.2:c.1_2insCCCA & NP_057171.2:p.(Met1?) & disease causing & $\mathrm{I}-1(\mathrm{~F})$ & \multirow[t]{12}{*}{ polygenic } \\
\hline CD248 & nonframeshift_deletion & NM_020404.2:c.1326_1328del & NP_065137.1:p.(Ser443del) & disease causing & $\mid-1(F)$ & \\
\hline COL6A5 & stopgain & NM_001278298.1:c.7772del & NP_001265227.1:p.(Leu2591Ter) & disease causing & $\mid-1(F)$ & \\
\hline ADAMTS3 & missense_SNV & NM_014243.2:C.181C > T & NP_055058.2:p.(Leu61Phe) & disease causing & $\mid-1(F)$ & \\
\hline COL4A3 ${ }^{\mathrm{a}}$ & missense_SNV & NM_000091.4:c.4607 T > C & $\begin{array}{l}\text { NP_000082.2(LRG_230p1): } \\
\text { p.(Ile1536Thr) }\end{array}$ & disease causing & I-2(M) & \\
\hline ADAMTS20 & missense_SNV & NM_025003.4:C.2228G > A & NP_079279.3:p.(Gly743Glu) & disease causing & $\mathrm{I}-2(\mathrm{M})$ & \\
\hline COL6A2 & splicing & NM_001849.3:c.1817-3dup & NP_001840.3(LRG_476p1):p.? & disease causing & I-2(M) & \\
\hline COL11A2 & splicing & $\begin{array}{l}\text { NM_080680.2:C.1819-18_ } \\
\text { 1819-9del }\end{array}$ & NP_542411.2:p.? & polymorphism & I-2(M) & \\
\hline COL23A1 & splicing & NM_173465.3:c.960 + 3dup & NP_775736.2:p.? & polymorphism & I-2(M) & \\
\hline COL18A1 & splicing & NM_030582.3:c.1279-7dup & NP_085059.2:p.? & polymorphism & $\mathrm{I}-2(\mathrm{M})$ & \\
\hline PTPRZ1 & nonframeshift_deletion & NM_002851.2:c.4290_4292del & $\begin{array}{l}\text { NP_002842.2(LRG_1387p1): } \\
\text { p.(Asp1431del) }\end{array}$ & disease causing & $\mathrm{I}-1(\mathrm{~F})$ or $\mathrm{I}-2(\mathrm{M})$ & \\
\hline ADAMTS16 & splicing & $\begin{array}{l}\text { NM_139056.3:c.1314-6_1314- } \\
\text { 5dup }\end{array}$ & NP_620687.2:p.? & polymorphism & $\mathrm{I}-1(\mathrm{~F})$ and $\mathrm{I}-2(\mathrm{M})$ & \\
\hline
\end{tabular}

Notes: $F$ proband's father, $M$ proband's mother, FPKM Fragments per kilobase of exon model per million mapped fragments, $N$-HCF normal HCF cells ${ }^{a}$ reported candidate gene 
reported $\mathrm{KC}$ pathogenesis. Finally, 12 gene variants belonging to specific GOs with similar functions were selected as the candidate genes under the polygenetic model (Fig. 3d). Six of these came from the mother (including the c.4607 $\mathrm{T}>\mathrm{C}$ in reported gene COL4A3), four from the father, and one from both, while the origin of the remaining gene was uncertain. Function prediction results from MutationTaster showed that four candidate gene variants were considered "polymorphisms," and eight were considered "disease causing" (Fig. 3d, Table 1).

\section{Expression and function analysis further confirmed the pathogenicity of the accumulation of multiple rare, micro-effect risk variants}

To further identify the putative pathogenicity of gene variants and detect the $\mathrm{KC}$ related gene function and pathway changes, the researchers conducted an expression analysis. Transcriptome sequencing (RNA-seq) on the proband's primary human corneal fibroblast cells (II1-HCF) and normal HCF cells were used to assess gene expression changes. All RNA samples were sequenced with 40.2-43.3 million raw reads, and all samples had at least 36 million reads aligned. Sequence reads with multiple alignments were removed during the quality control process. Out of the total 22,051 genes, 10,957 were expressed in the normal HCF cells with FPKM (Fragments Per Kilobase of transcript per Millionfragments mapped) $\geq 1.0$, and 11,142 were expressed in patient HCF cells with FPKM $\geq 1.0$. The Pearson correlation coefficient between samples was 0.97. Differential expression analysis identified 589 differentially expressed genes in II-1-HCF cells, with at least a two-fold change and a false discovery rate $p$ value $\leq 0.05$ (Fig. 4a, Additional file 2: Table S3).

Then, the expression levels of the candidate genes determined at the DNA level were analyzed. The results indicated whether each candidate gene was expressed in corneal cells, and weather each candidate gene variant affects the expression of itself or expression of its function related genes. PKDREJ, detected under the autosomal recessive model with uncertain significance, was essentially not expressed (FPKM $=0.11)$ in normal HCFs (Fig. 4b). No significant difference was detected in the expression of its top 20 associated genes between the proband and normal HCF cells (Fig. 4b). In addition, $P K D R E J$ and its associated genes did not have any same or similar function with the reported pathogenesis of KC. All of these suggest that PKDREJ is not the pathogenic gene in the sampled $K C$ family.

Similarly, FGA, detected under the de novo mutation model, was not expressed in both the proband and normal HCF cells (Fig. 4c), indicating that it may not be involved in the structure and function of cornea. Although FGA and its top 20 associated genes have some similar functions with the reported pathogenesis of $\mathrm{KC}$, many of them was essentially not expressed in HCF cells (Fig. 4c). The expression levels of rest genes also had no significant difference between the proband and normal HCF cells (Fig. 4c). All of these results suggest that FGA is not the pathogenic gene in the sampled KC family too.

The FPKM values of the 12 candidate genes detected under the polygenetic model are shown in (Fig. 4d). Among them, 8 candidate genes (COL23A1, CD248, ADAMTS16, ADAMTS3, COL4A3, COL18A1, WNT16, and COL6A2) were expressed in corneal cells. There was no significant difference in the expression of candidate genes between the proband and normal HCF cells (Fig. 4d). Among their top 20 associated genes, 5 genes (ADAMTS1, ADAMTS5, ADAMTS10, ADAMTS15, and COL4A1) showed significant differential expression (Fig. $4 \mathrm{~d})$. In addition, these candidate genes and their top 20 associated genes were enriched in many similar functions with the reported pathogenesis of $\mathrm{KC}$. These results suggested that these variants did not affect the expression of themselves, but affected the expression of function related genes, then caused the functional changes consistent with the known pathogenesis of $\mathrm{KC}$, which will undoubtedly lead to development of KC. All of these suggested that the accumulation of multiple rare, micro-effect risk variants might be the pathogeny of the sampled KC family.

\section{Multi-level consistent changes of the ECM pathway identified by multi-omics analysis}

In order to further explore the molecular pathogenesis of $\mathrm{KC}$, we performed differential expression analysis and identified 589 differentially expressed genes in II-1-HCF cells, with at least a two-fold change and a false discovery rate $p$ value $\leq 0.05$ (Additional file 2: Table S3). There were 300 downregulated and 289 upregulated genes in the proband HCF cells. Gene ontology analysis using the 300 downregulated genes indicated that the top five significant enrichments of the genes coding for proteins were involved in or related to the proteinaceous ECM (adjust $p$ value (padj): 5.56E-09), the ECM (padj: 4.02E-08), the ECM structural constituent (padj: 3.46E-06), the ECM component (padj: 2.49E-05), and the aminoglycan catabolic process (padj: 3.64E-03) (Fig. 5a). Gene ontology analysis using the 289 upregulated genes indicated that the top five significant enrichments of genes coding for proteins were involved in or related to the regulation of the hormone metabolic process (padj: 2.97E-03), the positive regulation of bone mineralization (padj: 3.00E-03), the positive regulation of biomineral tissue development (padj: 3.00E-03), the regulation of bone mineralization (padj: 3.00E-03), and the regulation of biomineral tissue development (padj: 3.00E-03) (Fig. 5b). Kyoto Encyclopedia of Genes and Genomes (KEGG) pathway analysis using all 


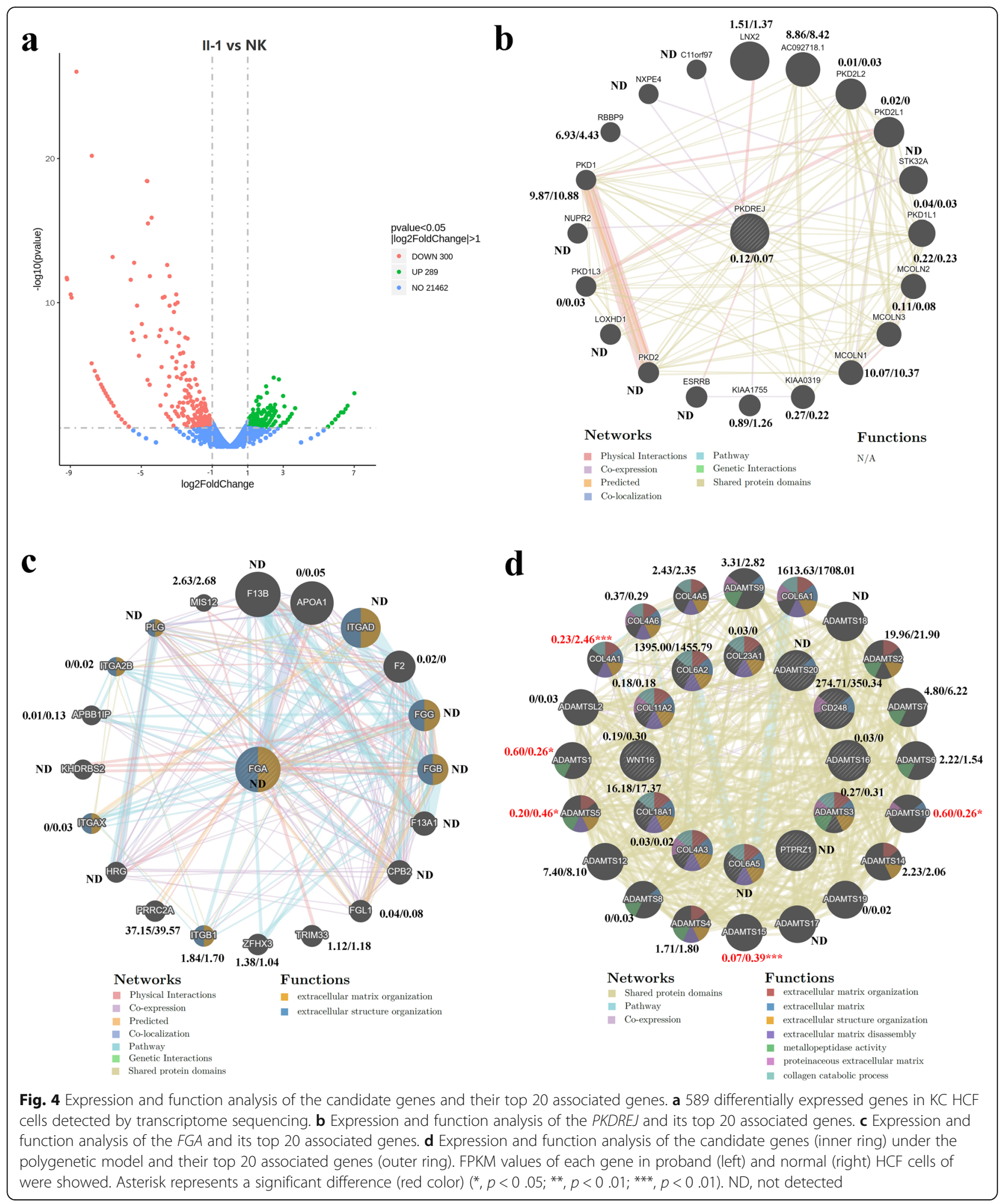

589 genes identified the enriched pathways, including protein digestion and absorption and the TGF-beta signaling pathway (Fig. 5c). Reactome analysis using all 589 genes indicated the involvement of ECM organization, GPCR downstream signaling, degradation of the ECM, and elastic fiber formation (Fig. 5d).

Combined analysis of exome and transcriptome enrichment revealed their shared GOs and pathways, allowing 
$\mathbf{a}$

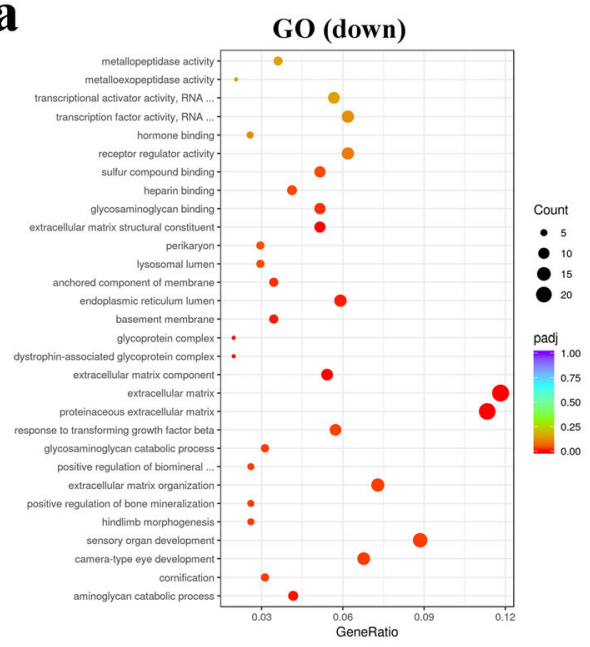

c

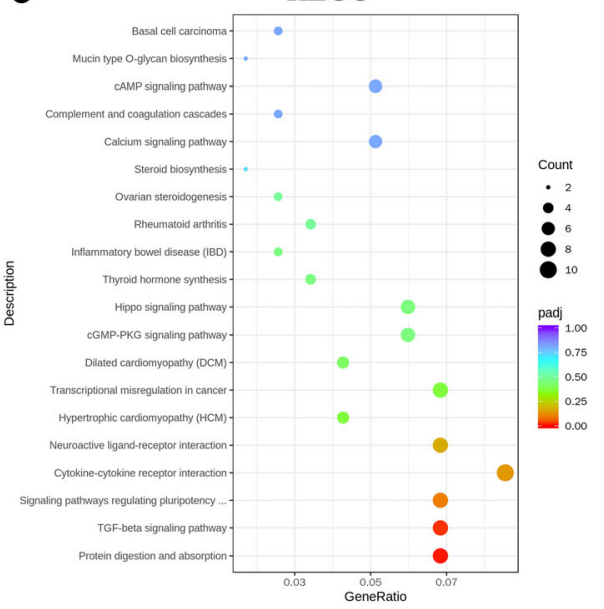

e

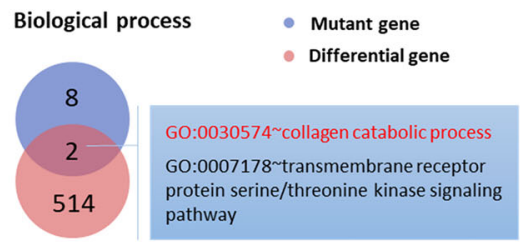

Cell compoment

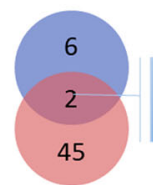

GO:0005578 proteinaceous extracellular

matrix

GO:0005581 collagen trimer

Molecular function

\section{$\begin{array}{lll}7 & 0 & 91\end{array}$}

b

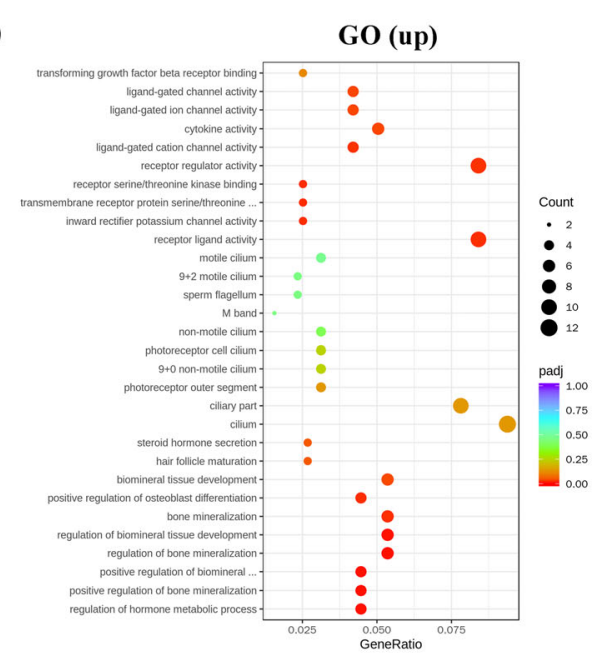

d

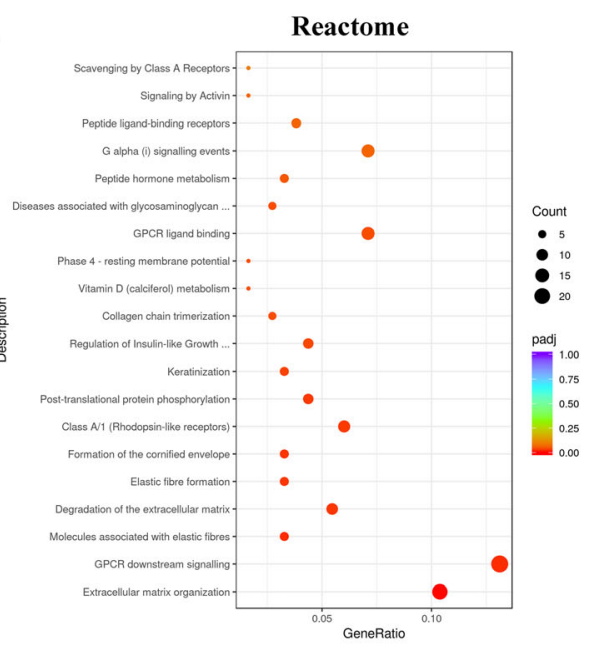

f
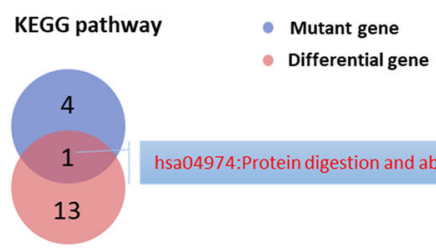

hsa04974:Protein digestion and absorption

Reactome pathway

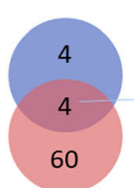

R-HSA-1650814:Collagen biosynthesis and modifying enzymes

R-HSA-1442490:Collagen degradation

R-HSA-2022090: Assembly of collagen fibrils and other multimeric structures

R-HSA-5173214:O-glycosylation of TSR domain-containing proteins

Fig. 5 (See legend on next page.) 
(See figure on previous page.)

Fig. 5 Consistent changes of the ECM pathway identified by multi-omics analysis. a Top ten enriched GOs (each category) of 300 downregulated genes. b Top ten enriched GOs (each category) of 289 upregulated genes. c TOP 20 enriched KEGG pathways of differentially expressed genes. d TOP 20 enriched Reactome pathways of differentially expressed genes. e The shared GOs of candidate variant genes and differentially expressed genes. The GOs having similar functions with the reported pathogenesis of KC are indicated by red color. $\mathbf{f}$ The shared KEGG and Reactome pathways of candidate variant genes and differentially expressed genes. The pathways having similar functions with the reported pathogenesis of KC are indicated by red color

the researchers to evaluate candidate pathogenic factors in depth and lock onto pathogenic targets. The shared GOs of exome and transcriptome sequencing results are shown in Fig. 5e, including the two biological processes and two cell components. In these shared GOs, 75\% (including the collagen catabolic process, collagen trimer, and the proteinaceous ECM) had similar functions with the reported pathogenesis of $\mathrm{KC}$. The combined analysis of the KEGG pathway showed that protein digestion and absorption was significantly enriched both at DNA and RNA levels (Fig. 5f). The combined analysis of the Reactome pathway showed that there were four pathways shared by exome and transcriptome sequencing results, among which $75 \%$, including collagen biosynthesis and modifying enzymes, collagen degradation, and the assembly of collagen fibrils and other multimeric structures, had similar functions with the reported pathogenesis of KC (Fig. 5f). Most GO and pathway enrichments shared at DNA and RNA levels were related to collagen and the ECM, suggesting that these GO and pathway changes might have been etiological-serving as mechanisms of $\mathrm{KC}$ in this family.

\section{Validation of differential gene expressions involved in the ECM pathway}

The researchers further validated the differential gene expressions by selecting 18 genes involved in the ECM pathway (FBN2, COL4A1, GPC3, BMP4, COL4A2, TNXB, ELN, FMOD, VIT, PTN, GPC4, FBLN2, COL8A2, PRELP, ACAN, MFAP5, ADAMTS15, and MMP3) with top $p$ values. These were compared to the RNA-Seq results with RNA expression in the proband and in three normal HCF cells using qRT-PCR. Among the genes tested, 16 genes' expression levels (FBN2, COL4A1, BMP4, COL4A2, TNXB, ELN, FMOD, VIT, PTN, GPC4, FBLN2, PRELP, ACAN, MFAP5, ADAMTS15, and $M M P 3)$ in the proband cells were consistently lower or higher than in all controls (Fig. 6a), which were consistent with this study's RNA-Seq findings.

To further mine for key pathogenic factors, the authors analyzed the intermediary network of all related genes, including 12 candidate variant genes and 32 differentially expressed genes in shared enrichments. The protein interaction network showed that most of the genes were gathered into two groups (Additional file 3: Figure S2). One group was the collagen family of genes (consisting of six variant genes and five differential genes), and the other was the ADAMTS family of genes (consisting of three variant genes and four differential genes). Genes with multiple network nodes are believed to play an important role in $\mathrm{KC}$ pathogenesis. The authors selected the top eight proteins (Collagen IV, COL15A1, COL8A2, ADAMTS5, ACAN, GPC3, ELN and MMP3) of the network nodes for western blot validation. The results showed that five proteins' levels (Collagen IV, COL15A1, ADAMTS5, GPC3 and ELN) in the proband cells were consistently lower than in all controls (Fig. 6b), which were consistent with this study's RNASeq findings.

\section{Discussion}

$\mathrm{KC}$ is a complex, genetically heterogeneous, multifactorial, degenerative disorder of the cornea [1-3]. Previous reports have detected more than 30 candidate genes and regions associated with $\mathrm{KC}[7,8]$. However, because of the disease's genetic heterogeneity and specificity, its genetic causes in most patients have not been effectively solved. In addition, the pathogenesis, under the coverage of genetic mutations, remains unclear. This has become the bottleneck of $\mathrm{KC}$ genetic etiology research, so it is very important to find a breakthrough point to explore the key pathogenic genes of $\mathrm{KC}$ and common pathogenesis. Therefore, this study used the family of twins as material, using, for the first time, multi-omics analysis, to systematically display the changes in $\mathrm{KC}$ candidate factors in patients at the DNA, RNA, and protein levels. These can evaluate candidate pathogenic factors in depth and lock onto pathogenic targets. By integrating genomics, transcriptome, and protein level data, the authors systematically analyzed multiple consecutive events in $\mathrm{KC}$, which would provide a better understanding of the molecular mechanisms and genetic bases of complex characters in $\mathrm{KC}$.

The twins in this study presented classic phenotypes, clear diagnoses, complete case data, and clinical samples, which are excellent materials for genetically studying $\mathrm{KC}$. The clinical symptoms in these twins were very typical and consistent, including corneal ectasia, thinning, superficial scarring, and a cone-shaped protrusion with Vogt's striae, Fleischer's ring, and Munson's sign. Their parents' symptoms were not pronounced enough to diagnose $\mathrm{KC}$, but they did present some subclinical manifestations, including larger corneal curvatures, back elevation, and thinner corneal thickness compared to 


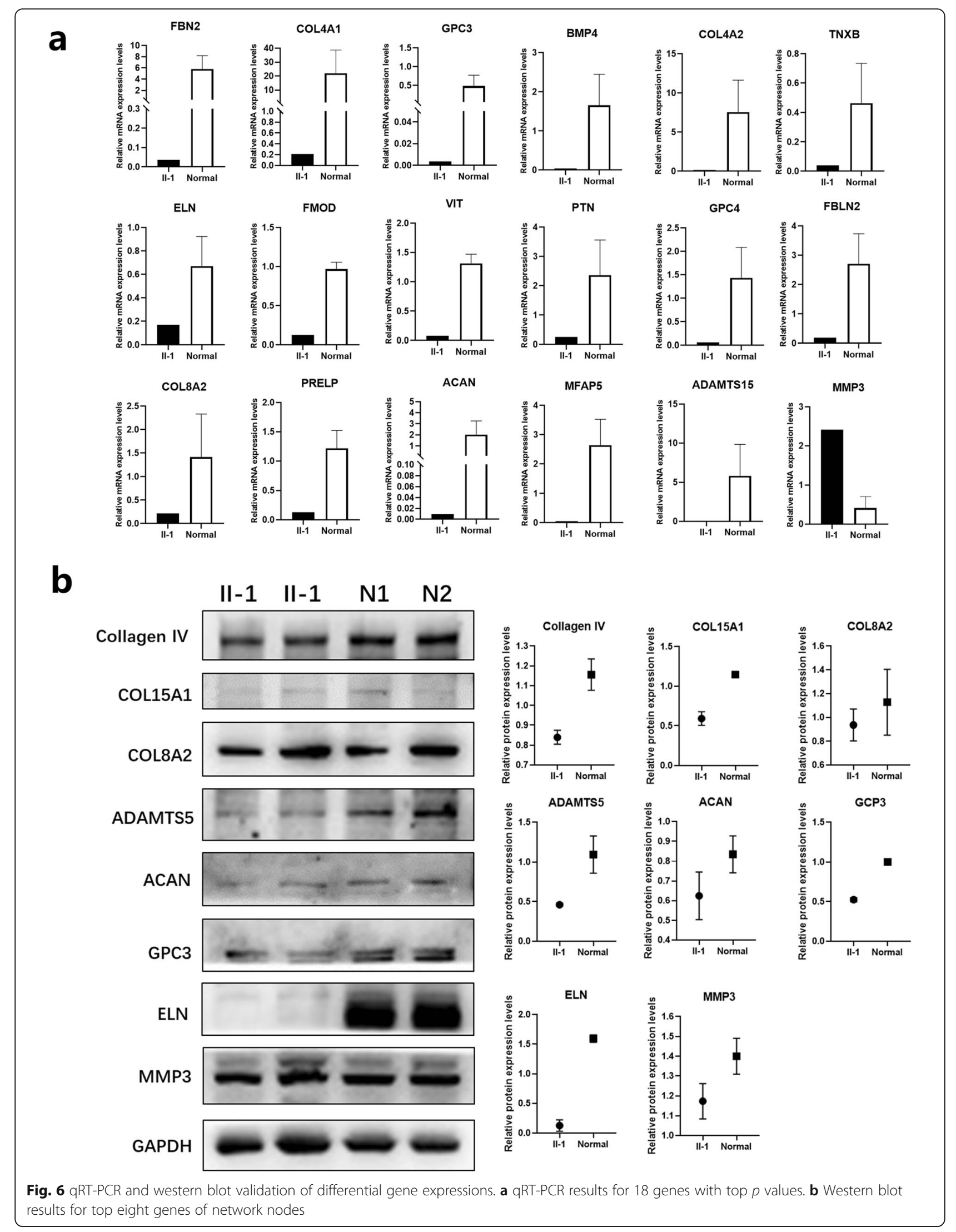


normal, unrelated individuals [29-31]. These complex clinical manifestations in this family supported the hypothesis of a polygenic inheritance pattern.

WES was conducted on both the twins and their parents. In addition to the traditional Mendelian genetic model, the polygenetic model and the de novo mutation model were also selected to screen for pathogenic genes at the DNA level, which greatly improved the possibility of detecting candidate gene mutations. Under the autosomal recessive model, the researchers identified the PKDREJ gene with rare compound heterozygous variants. However, one of the variants was considered a "polymorphism," as predicted by different tools. PKDREJ (full name: polycystin family receptor for egg jelly) is located on chromosome 22q13.31 and encodes a member of the polycystin protein family, which may have a central role in human fertilization [32]. A previous study has reported that PKDREJ has a very restricted expression pattern, and its transcript was found exclusively in testes [32]. The present transcriptome sequencing results also showed that this gene is essentially not expressed in the normal human cornea. All of this suggests that $P K D R E J$ is not the pathogenic gene in the sampled KC family. The authors also identified the FGA gene with a de novo variant in the functional region. Considering the benign functional prediction results and the absence of expression in HCF cells, the FGA gene was also eliminated as a candidate pathogenic gene in the sampled family.

Due to the combination of parental variants, the sampled twin patients received three specific collagen or ECM related GO enrichments compared to their parents. Changes in collagen and the ECM have been reported as being involved in $\mathrm{KC}[3,33-36]$. The accumulated variants of these three GOs may affect the normal function of collagens or ECMs, resulting in $\mathrm{KC}$ development. After screening specific and reported pathogeneses, which were functionally similar to the GOs in the sampled patients, the researchers detected 12 candidate gene variants under the polygenetic model. As predicted, some of these variants came from the twins' mother and some from their father. Among them, just five genes (WNT16, CD248, COL6A2, COL4A3, and ADAMTS3) were predicted as "disease causing" and expressed in normal HCF cells. Among them, COL4A3 is a reported candidate genes of $\mathrm{KC}[37,38]$. However, its variant was not cosegregation with the phenotype of the family, indicating that this variant cannot fully explain the cause of the disease. All of these suggested that the accumulation of these five gene variants were the key pathogenic factors at the DNA level.

The transcriptome sequencing results also showed that there were 589 differentially expressed genes in II-1HCF cells. For all the differentially expressed genes, in the top five enriched GOs, four were involved in or related with the ECM, and, in the top 5 enriched pathways, four were involved in or related with the ECM or elastic fibers. These results were consistent with previous studies, indicating that the expression changes of the genes related to the ECM play an important role in the KC pathogenesis and development [34, 35]. In addition, the GPCR downstream signaling pathway and the regulation of the hormone metabolic process were the next most significantly enriched pathways and GOs. This suggested that they may also be involved in $\mathrm{KC}$ development. Hormone changes have been reported as affecting corneal structure and $\mathrm{KC}$ [3]. However, no other literature or evidence supports the relationship between the GPCR downstream signaling pathway and KC.

Multi-omics analysis is an effective strategy for studying the pathogenesis of complex diseases [25-27]. To further explore the genetic etiology of $\mathrm{KC}$ and reveal its pathogenesis, the researchers conducted a combined analysis of exome and transcriptome sequencing results. The shared GOs and pathways of exome and transcriptome changes were the possible causes of $\mathrm{KC}$ pathogenesis. Combined analysis of exome and transcriptome enrichment found four shared GOs and four Reactome pathways. $75 \%$ of these GOs, including the collagen catabolic process, collagen trimer, and the proteinaceous ECM, were involved in or related to collagen or the ECM. $75 \%$ of these Reactome pathways, including collagen biosynthesis and modifying enzymes, collagen degradation, and the assembly of collagen fibrils and other multimeric structures, were also involved in or related to collagen. These suggested that these GO and pathway changes might be etiological-serving as $\mathrm{KC}$ mechanisms in the sampled family.

The protein interaction network of genes in shared enrichments showed that most of the genes were gathered into two groups. One group was the collagen family of genes, and the other was the ADAMTS family of genes. In the collagen family genes, COL6A2 and COL4A3 were expressed in normal HCF cells and also had "disease causing" variants in patients. The changed COL6A2 and COL4A3 protein may also have affected the expression of other related collagen proteins, such as COL4A1, COL4A2, COL15A1 etc. (verified both by qRT-PCR and western blot), thus reducing the number of ECMs within the patients' corneas. In the ADAMTS family of genes, only ADAMTS3 was expressed in normal HCF cells (FPKM values $>0.3$ ) and also had "disease causing" variant in the sampled patients. The mutated ADAMTS3 protein may also have affected the expression of other ADAMTS members (such as ADAMTS10) and, thus, reduced their substrates or the expressions of other related proteins (also validated by qRT-PCR), including aggrecan (ACAN: ECM components which could protect 
collagen fibrils from degradation by collagenases) [39], TNXB (ECM glycoproteins) [40], FMOD (interaction proteoglycans for ECM assembly), and PRELP (binding protein in ECM) (https://www.uniprot.org/). In addition, there was a group of genes interacting with both the collagen family and the ADAMTS family in the protein interaction network. All of the downregulated expression genes (validated by qRT-PCR or western blot) in this group were also involved or related with ECM, such as ELN (elastic fibers: part of the ECM) [41], FBLN2 (an ECM protein), MFAP5 (a component of microfibrils of the ECM), and FBN2 (a component of microfibrils for elastic fiber assembly) (https://www.uniprot.org/). Collagen is the main component of cornea stroma, and ECM changes are an important pathogenesis factor for $\mathrm{KC}$ $[33,34]$. These changes undoubtedly play a major role in stromal thinning and Bowman's layer/basement membrane breaks, which are characteristic of $\mathrm{KC}$ corneas.

\section{Conclusions}

To the best of the authors' knowledge, this study is the first to explore the candidate pathogenic genes and pathogenic mechanisms of $\mathrm{KC}$ by multi-omics analysis. Multi-omics analysis can realize and display the expression levels of candidate genes determined at the DNA levels, analyze the different expressions of mutated genes at the RNA level, and facilitate the enrichment analysis of key genes at the GOs and pathways, etc. Integrating genome, transcriptome, and protein level data allowed the researchers to systematically analyze multiple successive disease events. According to the changes of candidate factors at different levels, candidate pathogenic factors can be mined in depth to lock onto a pathogenic target. Thus, multi-omics analysis is an effective strategy for studying $\mathrm{KC}$ pathogenesis. Via multi-omics analysis, the authors identified multiple gene variants (WNT16, CD248, COL6A2, COL4A3, and ADAMTS3) as candidate genes in the sampled $\mathrm{KC}$ family, which suggested that the polygenetic model was the inheritance pattern for this $\mathrm{KC}$ and should be considered when detecting pathogenic genes in the future. Multi-level, consistent changes in the ECM pathway in this typical Chinese family with $\mathrm{KC}$ twins suggested that these ECM pathway changes play a key role in KC pathogenesis. In addition to collagens, other ECM related changes, such as decreases in aggrecan, glycoproteins, interaction proteoglycans, binding protein, elastic fibers, and microfibrils, also play an important role in $\mathrm{KC}$ pathogenesis, which provides new insights into the molecular mechanisms underlying $\mathrm{KC}$ and, therefore, must be given more attention. This study extends the existing spectrum of disease-causing genes and further defines the genotype-phenotype correlations. It not just worth for this family, but also provides new insights into the genetic etiology and molecular mechanisms underlying $\mathrm{KC}$, which will provide theoretical basis for the clinical diagnosis, treatment and epidemiological investigation. On the other hand, the new genetic model (the polygenetic model) and research method (multi-omics analysis) also provide an effective strategy for studying $\mathrm{KC}$ etiopathogenesis in the future.

\section{Methods}

\section{Subject recruitment and clinical examination}

This study was performed in accordance with the Declaration of Helsinki and approved by the Ethics Committee of Shandong Eye Institute (Qingdao, China). Written informed consent was obtained from all participants (or their guardians). Patients diagnosed with $\mathrm{KC}$ were recruited from Qingdao Eye Hospital (Qingdao, China). KC diagnosis was based on clinical examination (corneal stromal thinning, Vogt's striae, Fleischer's ring, Munson's sign, signs of videokeratography, and refractive errors). In total, the family of one pair of monozygotic twins was collected. The pedigree (Fig. 1a) suggested that the inheritance pattern among the twins' family was autosomal recessive, de novo mutation, or polygene mutations. Peripheral blood samples from all participating individuals were collected in EDTA (Ethylene diamine tet raacetic acid) tubes, and genomic DNA was extracted with a Blood DNA Kit (Tiangen Biotech Co., Beijing, China).

\section{Whole-exome sequencing (WES) and data analysis}

WES was conducted among all members of this family (the twins and their parents) at Novogene (Beijing, China) to identify the KC causal gene. The SureSelect Human All ExonV5 Kit (Agilent Technologies, USA) was used for exome capture, and the IlluminaHiseq 2500 platform (Illumina Inc., San Diego, CA, USA) was employed for the genomic DNA sequencing of the twins and their parents. Then, data analysis was conducted, and filtering was applied, following the filtering strategy described in the previous study [12]. Considering the incidence rate $(0.0005)$ of $\mathrm{KC}$, variants were common $(\mathrm{MAF}>1 \%)$ in dbSNP, and the 1000 Genomes Project were filtered according to reported guidelines for the interpretation of sequence variants $[28,42]$.

Given the characteristics of the family's pedigree, homozygous, compound heterozygous, or de novo variations were considered the first to be considered as candidate causal variations [43]. All candidate variants were submitted to Tolerant (SIFT) [44], PolyPhen-2 [45], and Mutation Taster [46] for functional prediction. At the same time, all other variations among the family members were collected for GO and pathway analysis via the online Database for Annotation, Visualization, and Integrated Discovery (DAVID) software, version 6.8 [47, 48]. By comparing the $\mathrm{KC}$ twins with their non-KC parents, the specific GOs and pathways of the patients could be 
determined. Gene variants belonging to GOs or pathways having similar functions with known $\mathrm{KC}$ pathogenesis were selected as the candidate genes for the polygenetic model. Sanger sequencing and genotyping of the candidate genes detected by WES were performed, as described in the previous study [12]. According to these results, the possible genetic model and candidate gene variants in this family were determined at the DNA level.

\section{Transcriptome sequencing and data analysis}

Normal primary human corneal fibroblast (N-HCF) and primary corneal fibroblast cells of II-1 (II-1-HCF) were isolated from normal and proband (II-1) corneas, as described previously [49], and cultured in a DMEM/F12 medium (Corning, USA) containing 10\% fetal bovine serum (FBS) (Gibco, USA) at $37^{\circ} \mathrm{C}$ with $5 \% \mathrm{CO}_{2}$. For the isolation of normal human corneal fibroblast cells, corneal tissues were obtained from the Eye Bank at Shandong Eye Institute. Corneal epithelium and endothelium were removed by digestion with $50 \mathrm{mg} / \mathrm{ml}$ dispase II (Roche, Switzerland) overnight at $4{ }^{\circ} \mathrm{C}$ [49]. The corneal stroma was cut into pieces and incubated $6-8 \mathrm{~h}$ at $37^{\circ} \mathrm{C}$ in DMEM/F-12 medium containing $1.25 \mathrm{mg} / \mathrm{ml}$ collagenase (Invitrogen, USA), until the tissue smeared onto the dish bottom [49]. For the proband, corneal tissues were obtained from Qingdao Eye Hospital, Shandong Eye Institute (Qingdao, China), and the corneal fibroblast cells were isolated as described above immediately after operation. Total RNA was prepared from NHCF and II-1-HCF samples using the NucleoSpin RNA II System (Macherey-Nagel, Duren, Germany). RNA-seq was also conducted in these two type cells at Novogene (Beijing, China) to identify expression changes in the causal gene. The NEBNext ${ }^{\circ}$ UltraTM RNA Library Prep Kit (NEB, USA) was used to generate sequencing libraries, and the TruSeq PE Cluster Kit v3-cBot-HS (Illumia) was used to cluster the index-coded samples. Then the library preparations were sequenced on an Illumina Novaseq platform, and $150 \mathrm{bp}$ paired-end reads were generated. FeatureCounts v1.5.0-p3 was used to count the number of reads mapped to each gene. Then FPKMs for each gene were calculated based on the length of the gene and reads count mapped to the gene. The differences in gene expression between proband and normal HCFs was analyzed using the edgeR $\mathrm{R}$ package (3.18.1) to determine the specific genes associated with $\mathrm{KC}$, and the biological significance of these specific genes was analyzed by GO and pathway enrichment using the clusterProfiler R package.

\section{Combined analysis of exome and transcriptome sequencing}

The expression levels of the candidate genes, determined at the DNA level, were analyzed and displayed by Excel drawing. These results indicated whether each candidate gene was expressed in corneal cells and whether the expression level of candidate genes in the $\mathrm{KC}$ patients' corneal cells were significantly different compared to normal corneal cells. On the other hand, to determine whether there were corresponding functional changes caused by candidate gene variants in the KC patients, their top 20 associated genes' expression at the RNA levels were also screened and analyzed. The top associated genes and functions of candidate genes were predicted by GeneMANIA software [50]. Combined analysis of exome and transcriptome sequencing results revealed their shared GOs and pathways, allowing the authors to explore the possible pathogenesis of $\mathrm{KC}$.

\section{Quantitative real-time PCR}

Quantitative Real-time PCR (qRT-PCR) was used to verify the expression differences between related genes. cDNA was synthesized from RNA using a commercial kit (PrimeScript TM RT Reagent Kit (Perfect Real Time); Takara, Dalian, China). Expressions of the $\mathrm{KC}$ related genes, determined at the RNA levels, were measured by qRT-PCR and normalized to glyceraldehyde-3-phosphate dehydrogenase (GAPDH). Primer sequences of the genes used for qRTPCR are shown in Additional file 1: Table S2.

\section{Western blot}

To verify the changes of gene function and pathways in protein levels, western blot analyses were performed, as described previously [12]. First, the researchers collected corneal cells from normal individuals and from the family of the KC twins, extracted the total protein using radioimmunoprecipitation assay (RIPA) buffer (Galen, Beijing, China). For each sample, the levels of proteins of interest were normalized to that of GAPDH. Primary antibodies included Collagen IV antibody (ab6586, Abcam), COL15A1 antibody (D162738, Sangon Biotech), COL8A2 antibody (D262652, Sangon Biotech), ACAN antibody (A8536, Abclonal), ADAMTS5 antibody (D260094, Sangon Biotech), ELN antibody (D120588, Sangon Biotech), GPC3 antibody (A1496, Abclonal), MMP3 antibody (ab52915, Abcam), and antiGAPDH antibody (KC-5G5, Kangchen, Shanghai, China).

\section{Supplementary information}

Supplementary information accompanies this paper at https://doi.org/10. 1186/s13023-020-01512-7.

Additional file 1: Table S1. Clinical characteristics of members of the KC twins' family. Table S2. The primers for Quantitative Real-time PCR (qRT-PCR). Figure S1. Sanger sequencing results of candidate gene variants.

Additional file 2: Table S3. Five hundred eighty-nine differentially expressed genes in $1 \mathrm{H}-1-\mathrm{HCF}$ cells with at least 2 -fold change and false discovery rate $p$ value $\leq 0.05$ 
Additional file 3: Figure S2. Protein interaction network between candidate variant genes (inner ring) and differential expression genes (outer ring) in shared enrichments.

\section{Abbreviations}

KC: Keratoconus; ECMs: Extracellular matrices; WES: Whole-exome sequencing; SNPs: Single-nucleotide polymorphisms; OD: Right eye; OS: Left eye; OCT: Optical coherence tomography; GO: Gene ontology; 1000G: 1000 Genomes; HCF: Primary human corneal fibroblast cells; FPKM: Fragments Per Kilobase of transcript per Millionfragments mapped; padj: adjust $p$-value; KEGG: Kyoto Encyclopedia of Genes and Genomes; qRT-PCR: Quantitative Real-time PCR; RNA-Seq: Transcriptome sequencing; EDTA: Ethylene diamine tet raacetic acid; DAVID: Database for Annotation, Visualization, and Integrated Discovery; FBS: Fetal bovine serum; GAPDH: Glyceraldehyde-3phosphate dehydrogenase; RIPA: Radioimmunoprecipitation assay

\section{Acknowledgements}

The authors are greatly indebted to the family who participated in this research.

\section{Authors' contributions}

$\mathrm{XDH}$ and $\mathrm{HG}$ designed the research. $\mathrm{XDH}, \mathrm{XNC}, \mathrm{PC}$ and $\mathrm{YYZ}$ performed the experiments. $\mathrm{XDH}, \mathrm{XNC}$ and $\mathrm{CW}$ analyzed the data and participated in the discussion. XDH and HG wrote and revised the paper. WYS analyzed the data and participated in the revision of the paper.

\section{Funding}

This study was supported by National Natural Science Foundation of China (81870639, 81570821 and 81500763), Key Project of National Natural Science Foundation of China (81530027), Taishan Scholar Program (20150215, 201812150), Innovation Project of Shandong Academy of Medical Sciences (2019RC009), China Postdoctoral Science Foundation (2019 M652311), speical support for post-doc creative funding in shangdong province, and Applied Research Program for Post-Doctoral in Qingdao.

\section{Availability of data and materials}

The datasets used and/or analysed during the current study are available from the corresponding author on reasonable request.

\section{Ethics approval and consent to participate}

This study was performed in accordance with the Declaration of Helsinki and approved by the Ethics Committee of Shandong Eye Institute (Qingdao, China).

\section{Consent for publication}

Written informed consent was obtained from all participants.

\section{Competing interests}

The authors declare no conflict of interest. The founding sponsors had no role in the design of the study; in the collection, analyses, or interpretation of data, in the writing of the manuscript, and in the decision to publish the results.

\section{Author details}

${ }^{1}$ Institute for Translational Medicine, The Affiliated Hospital of Qingdao University, College of Medicine, Qingdao University, Qingdao 266021, China. ${ }^{2}$ State Key Laboratory Cultivation Base, Shandong Provincial Key Laboratory of Ophthalmology, Shandong Eye Institute, Shandong First Medical University \& Shandong Academy of Medical Sciences, Qingdao 266071, China. ${ }^{3}$ Department of Human Anatomy, School of Basic Medicine, Qingdao University, Qingdao, China. ${ }^{4}$ Shandong Eye Hospital, Shandong Eye Institute, Shandong First Medical University \& Shandong Academy of Medical Sciences, Jinan 250021, China.

Received: 16 March 2020 Accepted: 13 August 2020

Published online: 31 August 2020

\section{References}

1. Rabinowitz YS. Keratoconus. Surv Ophthalmol. 1998;42(4):297-319.
2. Mas Tur V, MacGregor C, Jayaswal R, O'Brart D, Maycock N. A review of keratoconus: diagnosis, pathophysiology, and genetics. Surv Ophthalmol. 2017;62(6):770-83.

3. Sharif R, Bak-Nielsen S, Hjortdal J, Karamichos D. Pathogenesis of Keratoconus: the intriguing therapeutic potential of prolactin-inducible protein. Prog Retin Eye Res. 2018;67:150-67.

4. Bykhovskaya Y, Margines B, Rabinowitz YS. Genetics in Keratoconus: where are we? Eye Vis (Lond). 2016;3:16.

5. Rahman I, Carley F, Hillarby C, Brahma A, Tullo AB. Penetrating keratoplasty: indications, outcomes, and complications. Eye (Lond). 2009;23(6):1288-94.

6. Karolak JA, Gajecka M. Genomic strategies to understand causes of keratoconus. Mol Gen Genomics. 2017;292(2):251-69.

7. Valgaeren H, Koppen C, Van Camp G. A new perspective on the genetics of keratoconus: why have we not been more successful? Ophthalmic Genet. 2017;39:1-17.

8. Willoughby CE, Lechner J. Heredity of keratoconus. In: Reinhard T, Larkin F, editors. Corneal disease: recent developments in diagnosis and therapy. Heidelberg: Springer; 2013.

9. Tuft SJ, Hassan H, George S, Frazer DG, Willoughby CE, Liskova P. Keratoconus in 18 pairs of twins. Acta Ophthalmol. 2012;90(6):e482-6.

10. Burdon KP, Vincent AL. Insights into keratoconus from a genetic perspective. Clin Exp Optom. 2013;96(2):146-54.

11. Nielsen K, Hjortdal J, Pihlmann M, Corydon TJ. Update on the keratoconus genetics. Acta Ophthalmol. 2013;91(2):106-13.

12. Hao XD, Chen $P$, Zhang YY, Li SX, Shi WY, Gao H. De novo mutations of TUBA3D are associated with keratoconus. Sci Rep. 2017;7(1):13570.

13. Bykhovskaya $Y$, Fardaei M, Khaled ML, Nejabat M, Salouti R, Dastsooz H, Liu Y, Inaloo S, Rabinowitz YS. TSC1 mutations in Keratoconus patients with or without tuberous sclerosis. Invest Ophthalmol Vis Sci. 2017; 58(14):6462-9.

14. Lucas SEM, Zhou T, Blackburn NB, Mills RA, Ellis J, Leo P, Souzeau E, Ridge B, Charlesworth JC, Brown MA, et al. Rare, potentially pathogenic variants in ZNF469 are not enriched in Keratoconus in a large Australian cohort of European descent. Invest Ophthalmol Vis Sci. 2017;58(14):6248-56.

15. Kalantan H, Kondkar AA, Sultan T, Azad TA, Alsabaani NA, AlQahtani MA, Almummar A, Liu Y, Abu-Amero KK. Polymorphism rs13334190 in zinc finger protein 469 (ZNF469) is not a risk factor for keratoconus in a Saudi cohort. BMC Res Notes. 2017;10(1):652.

16. Nejabat M, Naghash P, Dastsooz H, Mohammadi S, Alipour M, Fardaei M. VSX1 and SOD1 mutation screening in patients with Keratoconus in the south of Iran. J Ophthalmic Vis Res. 2017;12(2):135-40.

17. Lucas SEM, Zhou T, Blackburn NB, Mills RA, Ellis J, Leo P, Souzeau E, Ridge B, Charlesworth JC, Lindsay R, et al. Rare, potentially pathogenic variants in 21 keratoconus candidate genes are not enriched in cases in a large Australian cohort of European descent. PLoS One. 2018;13(6):e0199178.

18. Lechner J, Bae HA, Guduric-Fuchs J, Rice A, Govindarajan G, Siddiqui S, Abi Farraj L, Yip SP, Yap M, Das M, et al. Mutational analysis of MIR184 in sporadic keratoconus and myopia. Invest Ophthalmol Vis Sci. 2013;54(8): 5266-72.

19. Aldave AJ, Yellore VS, Salem AK, Yoo GL, Rayner SA, Yang H, Tang GY, Piconell Y, Rabinowitz YS. No VSX1 gene mutations associated with keratoconus. Invest Ophthalmol Vis Sci. 2006;47(7):2820-2.

20. Aldave AJ, Bourla N, Yellore VS, Rayner SA, Khan MA, Salem AK, Sonmez B. Keratoconus is not associated with mutations in COL8A1 and COL8A2. Cornea. 2007;26(8):963-5.

21. Karolak JA, Gambin T, Rydzanicz M, Szaflik JP, Polakowski P, Frajdenberg A, Mrugacz M, Podfigurna-Musielak M, Stankiewicz P, Gajecka M. Evidence against ZNF469 being causative for keratoconus in polish patients. Acta Ophthalmol. 2016:94(3):289-94.

22. Farzadfard A, Nassiri N, Moghadam TN, Paylakhi SH, Elahi E. Screening for MIR184 mutations in Iranian patients with Keratoconus. J Ophthalmic Vis Res. 2016;11(1):3-7.

23. Sahebjada S, Schache M, Richardson AJ, Snibson G, MacGregor S, Daniell M, Baird PN. Evaluating the association between keratoconus and the corneal thickness genes in an independent Australian population. Invest Ophthalmol Vis Sci. 2013;54(13):8224-8.

24. Hao XD, Chen P, Chen ZL, Li SX, Wang Y. Evaluating the association between Keratoconus and reported genetic loci in a Han Chinese population. Ophthalmic Genet. 2015:1-5.

25. Homsy J, Zaidi S, Shen Y, Ware JS, Samocha KE, Karczewski KJ, DePalma SR, McKean D, Wakimoto H, Gorham J, et al. De novo mutations in congenital 
heart disease with neurodevelopmental and other congenital anomalies. Science. 2015;350(6265):1262-6.

26. Styrkarsdottir $U$, Helgason $H$, Sigurdsson $A$, Norddahl GL, Agustsdottir AB, Reynard LN, Villalvilla A, Halldorsson GH, Jonasdottir A, Magnusdottir A, et al. Whole-genome sequencing identifies rare genotypes in COMP and CHADL associated with high risk of hip osteoarthritis. Nat Genet. 2017;49(5): 801-5.

27. Starokadomskyy P, Gemelli T, Rios JJ, Xing C, Wang RC, Li H, Pokatayev V, Dozmorov I, Khan S, Miyata N, et al. DNA polymerase-alpha regulates the activation of type I interferons through cytosolic RNA:DNA synthesis. Nat Immunol. 2016;17(5):495-504

28. Richards S, Aziz N, Bale S, Bick D, Das S, Gastier-Foster J, Grody WW, Hegde $M$, Lyon E, Spector E, et al. Standards and guidelines for the interpretation of sequence variants: a joint consensus recommendation of the American College of Medical Genetics and Genomics and the Association for Molecular Pathology. Genet Med. 2015;17(5):405-24.

29. Ma R, Liu Y, Zhang L, Lei Y, Hou J, Shen Z, Yi X, Wang Y. Distribution and trends in corneal thickness parameters in a large population-based multicenter study of young Chinese adults. Invest Ophthalmol Vis Sci. 2018; 59(8):3366-74.

30. Garcerant D, Jimenez-Alfaro I, Alejandre N. Diagnostic sensitivity of different reference bodies when using Scheimpflug tomography in a myopic population with Keratoconus. J Ophthalmol. 2019;2019:2593404.

31. Golan O, Hwang ES, Lang P, Santhiago MR, Abulafia A, Touboul D, Krauthammer M, Smadja D. Differences in posterior corneal features between normal corneas and subclinical Keratoconus. J Refract Surg. 2018; 34(10):664-70.

32. Hughes J, Ward CJ, Aspinwall R, Butler R, Harris PC. Identification of a human homologue of the sea urchin receptor for egg jelly: a polycystic kidney disease-like protein. Hum Mol Genet. 1999;8(3):543-9.

33. Meek KM, Tuft SJ, Huang Y, Gill PS, Hayes S, Newton RH, Bron AJ. Changes in collagen orientation and distribution in keratoconus corneas. Invest Ophthalmol Vis Sci. 2005;46(6):1948-56.

34. Foster JW, Shinde V, Soiberman US, Sathe G, Liu S, Wan J, Qian J, Dauoud Y, Pandey A, Jun AS, et al. Integrated stress response and decreased ECM in cultured stromal cells from Keratoconus corneas. Invest Ophthalmol Vis Sci. 2018;59(7):2977-86.

35. Bykhovskaya Y, Gromova A, Makarenkova HP, Rabinowitz YS. Abnormal regulation of extracellular matrix and adhesion molecules in corneas of patients with keratoconus. Int J Keratoconus Ectatic Corneal Dis. 2016;5(2): 63-70.

36. Sharif R, Khaled ML, McKay TB, Liu Y, Karamichos D. Transcriptional profiling of corneal stromal cells derived from patients with keratoconus. Sci Rep. 2019:9(1):12567.

37. Abdullah OA, El Gazzar WB, Salem TI, Al-Kamil EA. Role of extracellular matrix remodelling gene SNPs in keratoconus. Br J Biomed Sci. 2020;77(1):13-8.

38. Valgaeren H, Koppen C, Van Camp G. A new perspective on the genetics of keratoconus: why have we not been more successful? Ophthalmic Genet. 2018;39(2):158-74.

39. Pratta MA, Yao W, Decicco C, Tortorella MD, Liu RQ, Copeland RA, Magolda R, Newton RC, Trzaskos JM, Arner EC. Aggrecan protects cartilage collagen from proteolytic cleavage. J Biol Chem. 2003;278(46):45539-45.

40. Egging D, van den Berkmortel F, Taylor G, Bristow J, Schalkwijk J. Interactions of human tenascin- $X$ domains with dermal extracellular matrix molecules. Arch Dermatol Res. 2007;298(8):389-96.

41. Duque Lasio ML, Kozel BA. Elastin-driven genetic diseases. Matrix Biol. 2018; 71-72:144-60.

42. MacArthur DG, Manolio TA, Dimmock DP, Rehm HL, Shendure J, Abecasis GR, Adams DR, Altman RB, Antonarakis SE, Ashley EA, et al. Guidelines for investigating causality of sequence variants in human disease. Nature. 2014; 508(7497):469-76

43. Fromer M, Pocklington AJ, Kavanagh DH, Williams HJ, Dwyer S, Gormley P, Georgieva L, Rees E, Palta P, Ruderfer DM, et al. De novo mutations in schizophrenia implicate synaptic networks. Nature. 2014;506(7487):179-84.

44. Ng PC, Henikoff S. SIFT: predicting amino acid changes that affect protein function. Nucleic Acids Res. 2003:31(13):3812-4.

45. Adzhubei I, Jordan DM, Sunyaev SR. Predicting functional effect of human missense mutations using PolyPhen-2. Curr Protoc Hum Genet. 2013; Chapter 7:Unit7.20
46. Schwarz JM, Rodelsperger C, Schuelke M, Seelow D. MutationTaster evaluates disease-causing potential of sequence alterations. Nat Methods. 2010;7(8):575-6.

47. Huang DW, Sherman BT, Lempicki RA. Systematic and integrative analysis of large gene lists using DAVID bioinformatics resources. Nat Protoc. 2009;4(1): 44-57.

48. Huang DW, Sherman BT, Lempicki RA. Bioinformatics enrichment tools: paths toward the comprehensive functional analysis of large gene lists. Nucleic Acids Res. 2009;37(1):1-13.

49. Zhou Q, Wang Y, Yang L, Wang Y, Chen P, Wang Y, Dong X, Xie L. Histone deacetylase inhibitors blocked activation and caused senescence of corneal stromal cells. Mol Vis. 2008;14:2556-65.

50. Warde-Farley D, Donaldson SL, Comes O, Zuberi K, Badrawi R, Chao P, Franz M, Grouios C, Kazi F, Lopes CT, et al. The GeneMANIA prediction server: biological network integration for gene prioritization and predicting gene function. Nucleic Acids Res. 2010;38(Web Server issue):W214-20.

\section{Publisher's Note}

Springer Nature remains neutral with regard to jurisdictional claims in published maps and institutional affiliations.
Ready to submit your research? Choose BMC and benefit from:

- fast, convenient online submission

- thorough peer review by experienced researchers in your field

- rapid publication on acceptance

- support for research data, including large and complex data types

- gold Open Access which fosters wider collaboration and increased citations

- maximum visibility for your research: over $100 \mathrm{M}$ website views per year

At BMC, research is always in progress.

Learn more biomedcentral.com/submissions 